\title{
Bronchodilator treatment of stable COPD: long-acting anticholinergics
}

\author{
W. Vincken
}

ABSTRACT: Since airflow obstruction in chronic obstructive pulmonary disease (COPD) is to some extent reversible, bronchodilators play an important role in the maintenance treatment of COPD the more they reduce hyperinflation and, as a result, improve dyspnoea and exercise capacity. Since parasympathetic activity is the dominant reversible component of airflow obstruction in COPD, inhaled short-acting anticholinergic agents (SAAC), in particular ipratropium, became an efficient and safe first-line treatment, especially when combined with a short-acting $\beta_{2}$-adrenergic receptor agonist. Even better results were obtained when combining the SAAC ipratropium to a long-acting $\beta_{2}$-adrenergic receptor agonist (LABA), once they became available.

Recently, tiotropium bromide, the first of a new class of selective and long-acting anticholinergic agents was introduced for once-daily maintenance treatment of COPD patients. Several large long-term randomised clinical trials comparing tiotropium to placebo as well as to the SAAC ipratropium and the LABA salmeterol, have confirmed the long-acting and superior bronchodilator effect of tiotropium without any evidence of drug tolerance developing. These studies also have clearly demonstrated that tiotropium positively affects several other important health outcomes, such as dyspnoea sensation, exercise capacity, utilisation of rescue bronchodilators, health-related quality of life, COPD exacerbations and hospitalisations because of exacerbations. The improvement in these real-life outcomes appears related to the reduction in both static and dynamic hyperinflation. In all these studies, tiotropium was well tolerated and safe; the only relevant side-effect encountered being dry mouth, usually mild and often transitory. Finally, it has been shown that the combination of tiotropium with a LABA affords superior bronchodilatation than both agents alone, indicating that both classes of longacting bronchodilators should be regarded as complements rather than opponents.

In conclusion, a sufficiently large and convincing database now exists to propose the once-daily long-acting anticholinergic tiotropium as first-line maintenance treatment for all chronic obstructive pulmonary disease patients in global initiative for chronic obstructive lung disease (GOLD)-class II and above, with a step-up to its combination with a long-acting $\beta_{2}$-adrenergic receptor agonist in case of suboptimal clinical effect.

KEYWORDS: Anticholinergic agents, bronchodilators, chronic obstructive pulmonary disease, tiotropium bromide, treatment

$\mathbf{P}$ rogressive worsening of airflow obstruction is a characteristic finding in chronic obstructive pulmonary disease (COPD). The resulting static and dynamic hyperinflation contributes to dyspnoea and exercise limitation. There is growing evidence that these and other important outcomes, such as health-related quality of life, exacerbation and hospitalisation rates, are favourably influenced by maintenance therapy with bronchodilators. The use of bronchodilators is now recommended as the cornerstone of maintenance treatment of COPD [1], since this disease is no longer regarded as one characterised by irreversible airflow limitation but rather as a disease with at least partial reversibility of airflow limitation.

Several classes of bronchodilators are available, in particular $\beta_{2}$-adrenergic receptor agonists, both short- or fast-acting (SABA) and long-acting (LABA); the antimuscarinic anticholinergics, also both short-acting (SAAC) and long-acting (LAAC); and oral slow-release theophylline. In the present review the role of inhaled anticholinergic bronchodilators, and in particular that of the newly developed LAAC tiotropium bromide (Spiriva ${ }^{\circledR}$, Boehringer Ingelheim Pharma $\mathrm{GmbH} \& \mathrm{Co}$. KG, Ingelheim, Germany), in the
CORRESPONDENCE

W. Vincken

Respiratory Division

Academic Hospital University of

Brussels (AZ VUB)

Laarbeeklaan 101

1090 Brussels

Belgium

Fax: 3224776840

E-mail: walter.vincken@az.vub.ac.be 
treatment of COPD will be discussed and compared with the other classes of available bronchodilators. To this purpose a historical or chronological approach will be used as different agents were developed and became available on the market at different time periods.

\section{RATIONALE FOR THE USE OF ANTICHOLINERGIC AGENTS IN COPD}

Anticholinergic drugs effect their activity by competitive blockage of muscarinic cholinergic receptors, thereby inhibiting the bronchoconstriction and bronchial hypersecretion brought about by the parasympathetic neurotransmitter acetylcholine.

Five muscarinic receptor subtypes $\left(\mathrm{M}_{1}\right.$ to $\left.\mathrm{M}_{5}\right)$ have been identified, three of which $\left(\mathrm{M}_{1}, \mathrm{M}_{2}\right.$ and $\left.\mathrm{M}_{3}\right)$ have been detected in the human lung. $\mathrm{M}_{1}$-receptors are located in autonomic ganglia, submucosal bronchial glands and alveolar walls, $\mathrm{M}_{2^{-}}$ receptors in post-ganglionic parasympathetic nerve endings, and $\mathrm{M}_{3}$-receptors in airway smooth muscle, submucosal bronchial glands and endothelial cells [2, 3]. These three receptor subtypes each serve a different physiological function [4]. Thus, binding of acetylcholine to the $\mathrm{M}_{1}$-receptors facilitates cholinergic neurotransmission in parasympathetic ganglia, and $\mathrm{M}_{3}$-receptor stimulation by acetylcholine results in bronchial smooth muscle contraction (bronchoconstriction) and bronchial hypersecretion. $\mathrm{M}_{2}$-receptors play a particular role since their stimulation by acetylcholine provides a negative feedback modulation of acetylcholine release, thereby somewhat moderating the cholinergic effects at the site of the $\mathrm{M}_{3}$-receptors in airway smooth muscle.

Even in normal lungs a mild degree of acetylcholine-induced bronchial smooth muscle contraction is present, referred to as the resting vagal bronchomotor tone, such that the administration of an anticholinergic drug to normal subjects will result in mild bronchodilatation. In COPD patients, vagal bronchomotor tone appears to be increased as evidenced from the relatively greater bronchodilating effect of an anticholinergic drug on this resting vagal bronchomotor tone. This finding may partly be explained by geometrical factors, i.e. the relatively greater effect of bronchodilation on structurally narrowed airways due to the fact that resistance is inversely proportional to radius to the fourth power.

In contrast to the situation in asthma, anticholinergic agents appear to be more potent bronchodilators than $\beta_{2}$-adrenergic receptor agonists in COPD. Serial administration of supramaximal doses of the anticholinergic agent atropine methonitrate, the SABA salbutamol, and their combination to patients with emphysema showed that the plateau of bronchodilatation achieved with the anticholinergic agent was significantly higher than that achieved with the adrenergic agent [5]. When the adrenergic agent was given first, additional bronchodilatation was achieved with subsequent use of the anticholinergic agent. When the anticholinergic agent was given first, no additional bronchodilatation was achieved with subsequent use of the adrenergic agent. When both agents were given simultaneously, the degree of bronchodilatation obtained was not higher than that obtained with the anticholinergic agent alone. These findings led the authors to conclude that parasympathetic activity is the dominant reversible component of airway obstruction in COPD [5]. However, the clinical use of anticholinergic agents with a tertiary compound structure, such as atropine, has been hampered by their narrow safety margins. This changed with the venue of the inhalable quaternary ammonium compound ipratropium bromide. Several authors have since confirmed that in patients with COPD the bronchodilating activity, both acute and over a long-term period, of the inhaled anticholinergic agent ipratropium bromide is larger than that of SABAs, such as metaproterenol and salbutamol [6, 7].

INHALED SHORT-ACTING ANTICHOLINERGICS IN COPD Inhaled SAACs, such as ipratropium bromide and the somewhat longer acting oxitropium bromide, have since long been used as bronchodilators in COPD. Besides a bronchodilating effect on the larger airways, as evidenced from modest but significant improvements in forced expiratory volume in one second (FEV1) and airway conductance, they often also improve forced vital capacity (FVC) and inspiratory capacity (IC). In many COPD patients the improvement in FVC is even larger than the improvement in FEV1. This so-called volume response, which most likely represents a bronchodilating effect on the small airways with subsequent reduction in trapped gas and hyperinflation, likely explains the improvements in dyspnoea and exercise tolerance often noted to be disproportionately larger than can be expected from the modest improvements in FEV1. In a double-blind placebo-controlled crossover study, O'DONNELl et al. [8] showed that in stable COPD patients nebulised ipratropium bromide resulted in significant improvements in spirometric variables (FEV1, FVC and IC improved by $7 \%, 10 \%$ and $14 \%$, respectively), exercise endurance time (which increased by $32 \%$ ) and exertional dyspnoea (Borg dyspnoea ratings decreasing by $11 \%$ ). The improvements in exercise endurance time and in exertional dyspnoea correlated with the increase in IC (reflecting reduced hyperinflation) but not with the improvements in the other spirometric variables, leading the authors to suggest the use of IC in conjunction with the FEV1 when evaluating therapeutic responses in COPD patients. Other authors have confirmed the beneficial effect of the SAACs ipratropium bromide [9] and oxitropium bromide [10] on exercise capacity and dyspnoea in COPD patients.

Inhaled SAACs possess a very good safety profile, which is an important feature to consider in the often elderly COPD patient population, frequently with associated cardiovascular disorders. Because of their quaternary ammonium compound structure, the ingested fraction of the SAACs is not absorbed in the gastro-intestinal tract and systemic availability mainly depends on the fraction deposited in the lungs. The only important side effect reported is dry mouth, while no impairment of mucociliary clearance could be demonstrated [11]. In contrast to SABAs, prolonged use of SAACs does not lead to tachyphylaxis or drug tolerance [6].

\section{THE COMBINATION OF A SAAC WITH A SABA}

Before the advent of long-acting bronchodilators, the combination of the SAAC ipratropium bromide with a SABA (fenoterol or salbutamol) became the preferred bronchodilator treatment in COPD patients. As shown in table 1, many reasons provide a good rationale for combining an anticholinergic agent and a $\beta_{2}$-adrenergic receptor agonist. Numerous studies have 


\begin{tabular}{|c|c|}
\hline TABLE 1 & $\begin{array}{l}\text { Rationale for combining an anticholinergic agent } \\
\text { and a } \beta_{2} \text {-adrenergic receptor agonist }\end{array}$ \\
\hline \multicolumn{2}{|c|}{$\begin{array}{l}\text { Different mechanisms of action } \\
\text { Parasympathetic versus sympathetic system }\end{array}$} \\
\hline \multicolumn{2}{|c|}{ Different sites of action (?) } \\
\hline \multicolumn{2}{|c|}{ Additive/synergistic effects } \\
\hline \multicolumn{2}{|c|}{ Onset and duration of activity } \\
\hline \multicolumn{2}{|c|}{ Limitation of dose and side-effects } \\
\hline \multicolumn{2}{|c|}{ Improved compliance } \\
\hline \multicolumn{2}{|c|}{ Cost-effectiveness } \\
\hline
\end{tabular}

demonstrated that the degree of bronchodilatation achieved with the combination is larger than that of either agent alone [12-17]. The more rapid onset of action of the SABA complements the more prolonged duration of action of the SAAC, and their combination usually allows dosage reduction of either component, thereby increasing safety margins $[13,14]$ and patient compliance [16]. Furthermore, the combination of ipratropium and albuterol (salbutamol) was shown to reduce exacerbation rates [18] and to result in appreciable cost savings [19]. For all these reasons the combination of ipratropium with a SABA, preferably in one inhalation device, became recommended both in the USA [20] and Europe [21] as first-line maintenance treatment for patients with COPD needing more than one bronchodilator. The problem inherent to regular treatment with short-acting bronchodilators even when combined into one device, however, is that multiple dosing (4-6 times per day) is necessary. Poor adherence to therapy is frequent among COPD patients who often are prescribed many other medications and, whenever possible, treatment regimens should be simplified [22, 23]. One possibility is the use of longer-acting agents allowing twice or even once-daily dosing.

\section{LONG-ACTING $\beta_{2}$-ADRENERGIC RECEPTOR AGONISTS IN COPD}

Some 10 yrs ago the twice-daily inhaled LABAs salmeterol and formoterol became available for maintenance treatment of COPD. Compared with placebo, regular treatment with salmeterol improved daytime and night-time respiratory symptoms, improved morning peak expiratory flow rate (PEFR) and spirometric values, and reduced rescue bronchodilator use [24-26]. Although the distance walked in 6 min was not increased, patients treated with the recommended dose of $50 \mu \mathrm{g}$ salmeterol twice daily perceived less breathlessness on exercise than those treated with placebo $[25,26]$. The modest changes in lung function were associated with a clinically significant gain in health-related quality of life in patients treated with $50 \mu \mathrm{g}$ salmeterol twice daily, an effect not seen in patients treated with $100 \mu \mathrm{g}$ salmeterol twice daily [27]. Adverse events were not different from placebo, except for tremor in the patients receiving $100 \mu \mathrm{g}$ salmeterol twice daily [26]. At clinically recommended doses, formoterol (12 $\mu \mathrm{g}$ twice daily) and salmeterol (50 $\mu \mathrm{g}$ twice daily) appear equally effective and safe bronchodilators in COPD patients with salmeterol displaying a somewhat longer duration of action and formoterol a somewhat more rapid onset of action [28-30].

\section{COMPARING LABAS TO THE SAAC IPRATROPIUM BROMIDE IN COPD}

In a 12-week randomised, double-blind, placebo-controlled clinical trial, MAHLER et al. [31] compared the LABA salmeterol twice daily to the SAAC ipratropium bromide four times per day in 411 symptomatic COPD patients with an FEV1 $<65 \%$ of predicted value. Both salmeterol and ipratropium reduced dyspnoea and the use of rescue albuterol. Salmeterol was significantly better than ipratropium in improving lung function and delaying the appearance of the first COPD exacerbation. In a similar study protocol, DAHL et al. [32] compared the LABA formoterol to the SAAC ipratropium bromide in 780 patients with COPD, concluding that formoterol was more effective in the treatment of COPD than ipratropium bromide, since the efficacy of formoterol on lung function translated more effectively into a clinically perceivable benefit than that of ipratropium bromide.

These findings led the authors to propose a LABA as first-line bronchodilator therapy for the long-term treatment of airflow obstruction in COPD patients [31, 32]. However, VAN NOORD et al. [33] showed that 12 weeks maintenance treatment with the combination of the LABA salmeterol and the SAAC ipratropium bromide was superior to salmeterol alone in terms of lung function and the incidence of exacerbations. Also, in patients requiring a combination of bronchodilators, the addition of the LABA formoterol to regular treatment with the SAAC ipratropium bromide was shown to be more effective in improving lung function and symptoms than the addition of the SABA salbutamol to the SAAC ipratropium bromide [34]. At that time point, optimal maintenance bronchodilator treatment in COPD appeared to be the combination of the SAAC ipratropium bromide and a LABA. In COPD patients, the LABA should not be used at higher than recommended doses for reasons of increased risk of side effects [26] on the one hand and loss of efficacy [27] on the other. In this regard the randomised, double-blind, placebo-controlled crossover study of LIESKER et al. [35] comparing 1-week treatment with the SAAC ipratropium bromide $80 \mu \mathrm{g}$ three times daily to three different dosages of the LABA formoterol $(4.5,9$ and $18 \mu \mathrm{g}$ twice daily) is of interest. Compared with placebo, both ipratropium bromide and all three doses of formoterol significantly improved lung function (spirometry and lung volumes) and exercise capacity measured as the time to exhaustion in an incremental cycle ergometer test. However, a negative dose-response relationship was observed with formoterol with regard to exercise capacity.

\section{PHARMACOLOGIC PROPERTIES OF THE LONG-ACTING ANTICHOLINERGIC TIOTROPIUM BROMIDE}

Although at present others are being developed, tiotropium bromide is as yet the first and only LAAC available for the treatment of COPD. Tiotropium bromide is a potent (up to 10 times the potency of ipratropium bromide) and reversible muscarinic cholinergic receptor antagonist that binds with equal affinity to the $\mathrm{M}_{1^{-}}, \mathrm{M}_{2^{-}}$and $\mathrm{M}_{3}$-receptors. The binding of tiotropium bromide to the muscarinic cholinergic receptors is much longer lasting than that of ipratropium bromide, e.g. the $\mathrm{M}_{3}$-receptor dissociation half-life of tiotropium bromide amounts to $34.7 \mathrm{~h}$ versus $0.26 \mathrm{~h}$ for ipratropium bromide [36]. Prolonged receptor binding of tiotropium bromide translates 
into a duration of action $>24 \mathrm{~h}$, making it the only available bronchodilator suitable for once-daily dosing. Another asset of tiotropium bromide is that it dissociates much more slowly from the $\mathrm{M}_{3^{-}}$and $\mathrm{M}_{1}$-receptors than from the $\mathrm{M}_{2}$-receptors, dissociation half-lives of $34.7 \mathrm{~h}, 14.6 \mathrm{~h}$ and $3.6 \mathrm{~h}$, respectively, having been recorded [37]. This results in a kinetic type of receptor-subtype selectivity of tiotropium bromide for $\mathrm{M}_{3}$ - and $\mathrm{M}_{1}$ - receptors over $\mathrm{M}_{2}$-receptors. Reminding that $\mathrm{M}_{2}$-receptors serve as a negative feedback for acetylcholine release, their inhibition by an anticholinergic agent results in increased acetylcholine release and bronchoconstriction. Hence, an anticholinergic agent, such as tiotropium bromide with relatively poor activity on $\mathrm{M}_{2}$-receptors, as compared with $\mathrm{M}_{3}$-receptors will display a stronger and longer-lasting bronchodilator effect.

In vitro studies comparing tiotropium bromide with atropine in isolated human bronchi confirmed that inhibition of smooth muscle cell contraction was slower in onset but far more potent and longer lasting for tiopropium bromide than for atropine [37]. In anaesthetised dogs, the protective effect of tiotropium bromide against acetylcholine-induced bronchoconstriction was more complete and longer lasting than that of ipratropium bromide [38].

Initial single dose studies using placebo and 9, 18, 36 and $72 \mu \mathrm{g}$ of inhaled tiotropium in patients with COPD confirmed the prolonged bronchodilator effect of tiotropium bromide, FEV1 values remaining above baseline for up to $72 \mathrm{~h}[39,40]$. Peak bronchodilation was dose dependent in these crossover studies, as well as after the first dose administered in the LITTNER et al. [41] multidose study. In this double-blind, placebo-controlled parallel group study, 169 patients with COPD were randomised to receive $0,4.5,9,18$ or $36 \mu \mathrm{g}$ inhaled tiotropium once daily for 4 weeks. Significant dose-related improvements in FEV1 occurred within $1 \mathrm{~h}$ after the first dose of tiotropium as compared with placebo. Over the 29 days of the study, all doses of tiotropium produced significant increases over placebo in PEFR and spirometric variables (peak, trough, and $6 \mathrm{~h}$ post-dose average FEV1 and FVC), without a significant difference between the different doses investigated [41]. In a double-blind, ipratropium-controlled, 1week study, VAN NOORD et al. [42] characterised the onset of pharmacodynamic steady state of tiotropium bromide in patients with COPD. They found that FEV1 steady state (i.e. an improvement on day 8 in trough FEV1 by $0.19 \mathrm{~L}$ or $18 \%$ above baseline) was reached within $48 \mathrm{~h}$, while FVC steady state was more delayed. Indeed, after $48 \mathrm{~h}$, trough FVC improvement was $70 \%$ of the improvement seen on day 8 (i.e. $0.67 \mathrm{~L}$ or $27 \%$ over baseline). From these findings, it was concluded that continued improvements in FVC (and, hence, hyperinflation) can be expected over and beyond the first week of treatment with tiotropium [42].

Following inhalation with the HandiHaler@ (Boehringer Ingelheim Pharma GmbH \& Co. KG) dry-powder device, $\sim 20 \%$ of the delivered dose of tiotropium bromide is deposited in the normal subject's and COPD patient's lung, from which it is rapidly absorbed in the systemic circulation [36]. However, plasma concentrations are low or undetectable without evidence of drug accumulation once steady state is achieved. Being a quaternary ammonium compound, only $2-3 \%$ of the ingested fraction of tiotropium bromide is absorbed in the gastro-intestinal tract. Plasma protein binding amounts to $70 \%$ and tiotropium does not cross the blood-brain barrier. It is almost not metabolised and is excreted in the urine in unmodified form. In case of renal insufficiency, increased tiotropium plasma levels may occur. Because of all these pharmacokinetic properties, systemic muscarinic side effects, such as inhibition of salivation, lacrimation and gastric secretion, and mydriasis, tachycardia and urinary retention, are limited after inhalation of tiotropium bromide.

On the basis of the comparable bronchodilator response at doses 9-36 $\mu \mathrm{g}$, and advantages suggested by the safety profile at doses $<36 \mu \mathrm{g}$ [41], a dose of $18 \mu \mathrm{g}$ once daily was selected for use in longer-term studies of the efficacy and safety of tiotropium in COPD patients.

\section{LONG-TERM CLINICAL TRIALS WITH THE LAAC TIOTROPIUM BROMIDE}

In order to investigate the long-term efficacy and safety of tiotropium bromide in patients with COPD, several similarly designed clinical trials have been conducted. In these studies, $18 \mu \mathrm{g}$ of tiotropium dry powder was inhaled once daily in the morning from a pierced capsule via the HandiHaler $₫$ device. Both in vitro and in vivo studies in COPD patients have shown the HandiHaler $\AA$ device to effectively deliver particles to the lung over a wide range of airflow limitation and at flow rates as low as $20 \mathrm{~L} \cdot \mathrm{min}^{-1}$ [43]. Tiotropium $18 \mu \mathrm{g}$ once daily for $1 \mathrm{yr}$ was compared in a randomised, double-blind, double-dummy fashion to placebo in two similarly designed USA studies and to the SAAC ipratropium bromide $40 \mu \mathrm{g}$ four times daily in two similarly designed Belgian-Dutch studies. Following partial 3-months interim analyses [44, 45], the pooled 1-yr results of the placebo-controlled USA studies have been reported by CASABURI et al. [46] and those of the ipratropiumcontrolled Belgian-Dutch studies by VINCKEN et al. [47]. In all these studies, patients aged $>40$ yrs with a smoking history of at least 10 pack-yrs and a clinical diagnosis of COPD were consecutively included. At baseline, the FEV1/FVC ratio had to be $<70 \%$ and the FEV $1<65 \%$ of predicted value. Patients with a history of asthma, allergic rhinitis, atopy or an elevated total blood eosinophil count were excluded, as were patients requiring regular supplemental oxygen and those with a recent upper respiratory tract infection or a significant disease other than COPD. Main primary endpoint was trough FEV1, calculated as the mean value of FEV1 measured 60 min and 5 min before administration of the morning dose. Trough FEV1 corresponds to the FEV1 $23-24 \mathrm{~h}$ after the preceding dose of tiotropium or placebo and 8-9 h after the preceding dose of ipratropium. Secondary endpoints included peak and 6-h average FEV1 and FVC following administration of the morning dose, trough FVC, dyspnoea rated according to Mahler's Transition dyspnoea Index (TDI) [48], use of the rescue SABA salbutamol, health-related quality of life using the disease-specific St. George's Respiratory Questionnaire (SGRQ) [49], and exacerbation and hospitalisation rates. It should be remembered that a 1 unit change in Mahler's TDI and a 4-unit change in Jones' SGRQ score indicate clinically relevant changes.

Patient characteristics at screening are shown in table 2. Mean age was $\sim 65$ yrs and baseline FEV1 was $\sim 40 \%$ of predicted 
TABLE 2 Patient characteristics at screening: 1-yr and 6-month trials with tiotropium

\begin{tabular}{|c|c|c|c|c|c|c|c|}
\hline & \multicolumn{2}{|c|}{ CASABURI et al. 2002 [46] } & \multicolumn{2}{|c|}{ VINCKEN et al. 2002 [47] } & \multicolumn{3}{|c|}{ Brusasco et al. 2003 [50] } \\
\hline & Tio & Pbo & Tio & Ipra & Tio & Sal & Pbo \\
\hline Patients $\mathbf{n}$ & 550 & 371 & 356 & 179 & 402 & 405 & 400 \\
\hline Male \% & 67 & 63 & 84 & 86 & 77 & 75 & 76 \\
\hline Age yrs & 65 & 65 & 64 & 65 & 64 & 64 & 65 \\
\hline FEV $1 \%$ pred & 39.1 & 38.1 & 43.9 & 41.4 & 39.2 & 37.7 & 38.7 \\
\hline FEV $1 /$ FVC $\%$ & 45.8 & 45.5 & 45.7 & 45.5 & 43.7 & 42.2 & 42.3 \\
\hline
\end{tabular}

Data are presented as mean, unless otherwise stated. Tio: tiotropium group; Pbo: placebo group; Ipra: ipratropium group; Sal: salmeterol group; COPD: chronic obstructive pulmonary disease; FEV1: forced expiratory volume in one second; FVC: forced expiratory volume.

value with a range indicating moderate to very severe COPD according to the updated global initiative for chronic obstructive lung disease (GOLD) guidelines [1]

In the placebo-controlled trials [46], tiotropium was shown to provide significant and prolonged bronchodilatation. Thus, the average FEV1 response during the first $3 \mathrm{~h}$ following dosing was $22 \%$ above baseline and the trough FEV1 response $23 \mathrm{~h}$ after dosing was $12 \%$ above baseline. FVC responses followed a similar pattern. This bronchodilator effect was maintained throughout the 1-yr study period without any evidence for the appearance of tachyphylaxis or drug tolerance. Furthermore, the bronchodilator effect of tiotropium was accompanied by both statistically and clinically significant reductions in dyspnoea scores and a statistically significant reduced need for rescue bronchodilators. Health-related quality of life improved statistically significantly in the tiotropium group with the difference in SGRQ total score from placebo almost reaching the clinically relevant 4 unit level. Percentage of patients with a greater than 4 unit improvement in SGRQ total score was significantly higher in the tiotropium than in the placebo group (49\% versus 30\%, respectively). Onset of first COPD exacerbation and first hospitalisation due to COPD was significantly delayed in tiotropium recipients compared with placebo recipients, and rates of exacerbation and hospitalisation due to a COPD exacerbation were significantly reduced by $20 \%$ and $44 \%$, respectively. Except for occurrence of dry mouth (in $16 \%$ of tiotropium patients versus $2.7 \%$ of placebo patients), adverse events were comparable in both groups [46]

In the trials comparing two active treatments, i.e. once daily tiotropium and four times daily ipratropium [47], the results obtained in the tiotropium recipients were almost identical to those obtained in the tiotropium recipients in the placebocontrolled trials [46]. Furthermore, in the ipratropiumcontrolled trials [47], tiotropium was clearly the better of both active treatments. Thus, in patients with a screening baseline FEV1 $\sim 1.2 \mathrm{~L}$, trough FEV1 at 1 yr improved by $0.12 \mathrm{~L}$ with tiotropium while it declined by $0.03 \mathrm{~L}$ with ipratropium, a statistically significant difference. Again, no evidence for tachyphylaxis or drug tolerance developing was seen. Significant improvements in PEFR, rescue salbutamol use, dyspnoea and health-related quality of life were seen with tiotropium. Significantly more patients receiving tiotropium attained the clinically relevant improvements in dyspnoea ( $31 \%$ versus $18 \%$ of ipratropium treated patients improved by more than 1 TDI unit) and health-related quality of life (52\% versus $35 \%$ of ipratropium treated patients improved by more than 4 SGRQ units). Compared with ipratropium, tiotropium significantly delayed the appearance of the first exacerbation and the first hospitalisation for an exacerbation, and significantly reduced the number of exacerbations (by 24\%) and the number of hospitalisations due to an exacerbation (by $38 \%$ ).

In a post hoc cost-effectiveness analysis [51] of the ipratropiumcontrolled studies [47], these favourable health outcomes obtained with tiotropium resulted in an additional cost of only $€ 180$ per patient per year [51].

Apart from a higher incidence of dry mouth in the tiotropium group, adverse events were similar for both treatments. Dry mouth was usually mild and often resolved with continued treatment.

\section{COMPARISON OF THE LAAC TIOTROPIUM BROMIDE TO THE LABA SALMETEROL}

In two similarly designed 6-month randomised, placebocontrolled, double-blind, double-dummy, parallel-group trials, the efficacy and safety of tiotropium bromide $18 \mu \mathrm{g}$ once daily via dry-powder inhaler was compared with that of the LABA salmeterol $50 \mu \mathrm{g}$ twice daily via metered-dose inhaler in COPD patients with an FEV1 $<60 \%$ of predicted value. One of these two studies was published separately by DONOHUE et al. [52], while the pooled results of both studies were later published by BRUSASCO et al. [50]. In the study by DONOHUE et al. [52] of 623 COPD patients [52], 6 months therapy with once-daily tiotropium significantly improved the pre-dose morning (trough) FEV1, the average (0-12 h) post-dose FEV1, the TDI focal score (by a clinically relevant 1.02 units) and the SGRQ total score (by 5.14 units) compared with placebo. The improvements in pre-dose morning (trough) FEV1, average (0-12 h) post-dose FEV1 and TDI focal score were significantly superior in the tiotropium group than those observed in the salmeterol group. A larger proportion of patients reached the clinically relevant 4 units improvement in SGRQ score in the tiotropium group compared with the salmeterol group [52]. 
These results were confirmed by the sudy by BRUSASCO et al. [50], pooling the results of 1,207 COPD patients equally divided in three parallel groups, i.e. tiotropium once daily, salmeterol twice daily and placebo (see table 2 for the demographic data at screening). While both active drugs were more effective than placebo in terms of pulmonary function, pre-dose morning (trough) FEV1, average ( $0-3 \mathrm{~h}$ ) post-dose FEV1 and peak post-dose FEV1 were superior in the tiotropium group as compared with the salmeterol group after 6 months of treatment, possibly as a result of drug tolerance developing towards the LABA salmeterol. Compared with placebo, TDI focal score improved significantly in both the tiotropium and the salmeterol group (by 1.1 and 0.7 units, respectively, at 6 months). In both active treatment groups, the percentage of patients reaching a more than 1 unit improvement in TDI focal score was significantly higher and the use of rescue salbutamol was significantly lower than in the placebo group. Healthrelated quality of life (SGRQ total score) improved significantly more in the tiotropium group (by 4.2 units) than in the placebo group (by 1.5 units), while the 2.8 units improvement in the salmeterol group was not statistically significantly different from that in the placebo group. Similarly, in the tiotropium group, but not in the salmeterol group, a significantly higher proportion of patients reached the 4 units improvement in the SGRQ total score as compared with placebo. In contrast to salmeterol, tiotropium significantly delayed the onset of the first COPD exacerbation as well as the number of COPD exacerbations per patient-year as compared with placebo [50].

These comparative studies, hence, provide evidence that longterm treatment of COPD patients with once-daily tiotropium translates more effectively in improvements in lung function and health outcomes such as dyspnoea and exacerbations than twice daily treatment with salmeterol, and, hence, may be considered the bronchodilator of choice in the maintenance treatment of COPD.

\section{THE COMBINATION OF A LABA WITH THE LAAC TIOTROPIUM}

In analogy to the superior results obtained with a combination of a short-acting anticholinergic and a short-acting $\beta_{2}$-adrenergic receptor agonist as compared with either drug alone, the combination of the LAAC tiotropium with a LABA deserves investigation in patients with COPD. Until now only two such studies have been reported in abstract form by VAN NOORD and collegues $[53,54]$. In the first of these studies, the lung function response to the free combination of tiotropium $18 \mu \mathrm{g}$ plus the LABA formoterol $12 \mu \mathrm{g}$ once daily was compared with that of tiotropium $18 \mu \mathrm{g}$ once daily alone and formoterol $12 \mu \mathrm{g}$ twice daily alone in a randomised, double-blind, double-dummy, three-way crossover study of 6-week periods in 74 COPD patients [53]. Twenty-four hour spirometry was performed at the end of each 6-week treatment period. It showed that the LAAC tiotropium provided significantly better bronchodilatation than the LABA formoterol during the daytime, confirming the data previously reported when comparing tiotropium to salmeterol $[50,52]$, and that tiotropium given once daily in the morning provided nocturnal bronchodilatation comparable to twice-daily treatment with formoterol. However, the free combination of both drugs taken once daily was superior to the single drugs in terms of daytime FEV1, both night-time FEV1 and FVC, and daytime use of rescue salbutamol [53].

In the second open label, randomised, three-way crossover study of 2-week periods, VAN NOORD et al. [54] compared in 95 COPD patients tiotropium $18 \mu \mathrm{g}$ once daily to the addition of formoterol $12 \mu \mathrm{g}$ once daily or formoterol $12 \mu \mathrm{g}$ twice daily. Again, 24-h spirometry was performed at the end of each 2week treatment period. The results showed that add-on therapy of the LABA formoterol once daily in the morning to tiotropium maintenance therapy significantly improved spirometric variables, including inspiratory capacity. Add-on therapy of a second formoterol dose in the evening further increased only some of these variables [54].

If confirmed by longer-term trials assessing health outcomes other than pulmonary function, these two studies appear to suggest that, as is already well established for short-acting bronchodilators, the combination of long-acting bronchodilators of two different classes might become the preferred maintenance treatment for COPD patients as from GOLD stage II on. These two studies also indicate that both classes of longacting bronchodilators, i.e. the LAAC tiotropium and the LABAs, should be regarded as complements or allies rather than as opponents for the maintenance treatment of COPD.

\section{TIOTROPIUM AND PHARMACOLOGICAL VOLUME REDUCTION}

Much of the beneficial effects of bronchodilators in general and tiotropium in particular on symptoms such as dyspnoea and exercise tolerance can be explained by a reduction in hyperinflation. By causing smooth muscle relaxation in central and peripheral airways, bronchodilators decrease airway resistance and increase tidal inspiratory and expiratory flow rates. The latter enhances lung emptying with each breath, thereby reducing air trapping and hyperinflation as indicated by an increased IC. The combined effects of increased tidal expiratory flow rates and reduced operating lung volumes permit the patient to achieve alveolar ventilation at a lower work of breathing and reduces dyspnoea sensation during rest and exercise, thereby increasing exercise endurance [55]. That these events effectively take place in COPD patients under tiotropium was recently shown by O'DONNELL et al. [56]. In a randomised placebo-controlled double-blind study in 187 patients, 7 weeks treatment with tiotropium $18 \mu \mathrm{g}$ once daily reduced static hyperinflation as shown by measurements of lung volumes. During exercise, dynamic hyperinflation was reduced, paralleling improvements in isotime Borg dyspnoea score and exercise endurance time by $21 \%$ [56]. CELLI et al. [57] showed that the improvements in static lung volumes in hyperinflated COPD patients using tiotropium once daily were maintained over a 24 -h period.

Improved exercise capacity may reverse the vicious downward spiral of dyspnoea-driven immobility and general deconditioning with further loss of exercise capacity. Improved exercise endurance also may allow the COPD patient to better cope with the activities of daily living, enhancing his/her selfsufficiency, ability to lead a more independent life and selfconfidence, and alleviating his/her social isolation and depression. All these secondary effects may beneficially influence the quality of the COPD patient's life (fig. 1). 


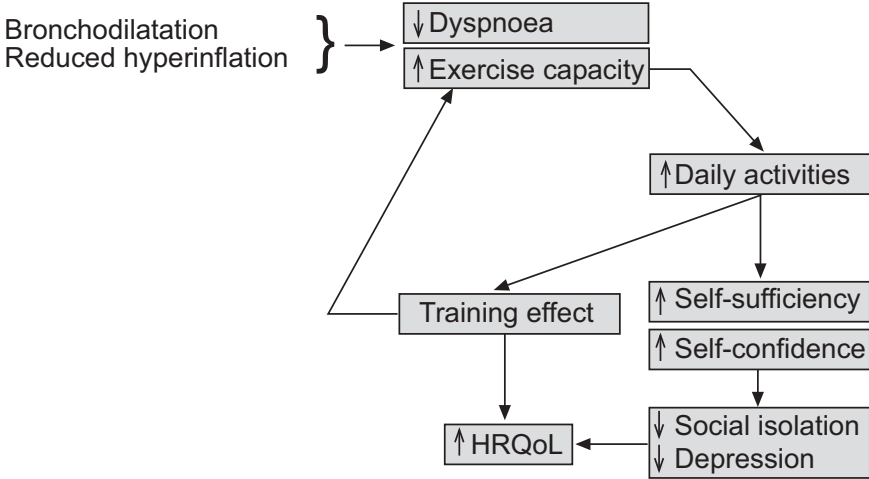

FIGURE 1. Hypothetical model of breaking the downward spiral of COPD patients. HRQoL: health-related quality of life.

\section{DOES TIOTROPIUM AFFECT THE NATURAL COURSE OF COPD?}

The only interventions that have been shown to positively influence the relentless decline in pulmonary function and the survival in COPD patients are smoking cessation and, to a lesser extent, long-term oxygen therapy in hypoxemic patients. For none of the existing pharmacological interventions does such proof exist. Whether tiotropium maintenance therapy can influence the natural course of COPD is as yet unknown. Several indirect indications suggest that tiotropium may be a disease-modifying agent. First, although residual bronchodilatation beyond $24 \mathrm{~h}$ might have been responsible, in the placebo-controlled 1-yr trial the decline in trough FEV1 in the tiotropium group was only $10 \mathrm{~mL}$ in the year that the study was conducted, as compared with the expected $40 \mathrm{~mL}$ decline in the placebo group [46]. Secondly, in all long-term trials tiotropium consistently reduced exacerbation (and hospitalisation) rates $[46,47,51,52]$. Exacerbations not only contribute substantially to the direct and indirect costs of COPD and are inconvenient for the patient, but also have been shown to affect the patient's health status and their annual decline in lung function $[58,59]$, thereby influencing their survival. Thirdly, in the ipratropium-controlled 1-yr trial the rate of deterioration of health status after an initial improvement appeared less in the tiotropium group than in the ipratropium group [47].

Currently, a large randomised, double-blind, placebo-controlled parallel group 4-yr trial comparing tiotropium with placebo in over 6,000 COPD patients, the UPLIFT study, is being conducted to assess the effect of tiotropium on the natural course, i.e. the long-term decline in lung function and the mortality of COPD.

\section{CONCLUSION}

Besides bronchodilatation per se, inhaled bronchodilators, probably by reducing hyperinflation both at rest and during exercise (a so-called pharmacological volume reduction effect), offer beneficial effects on real world outcomes important for the patient, such as symptoms (dyspnoea), exercise tolerance (endurance), exacerbation/hospitalisation rate and healthrelated quality of life. There now exists a sufficiently convincing database showing that these outcomes can be attained using maintenance treatment with once-daily inhaled tiotropium bromide, the first of a new class of long-acting and

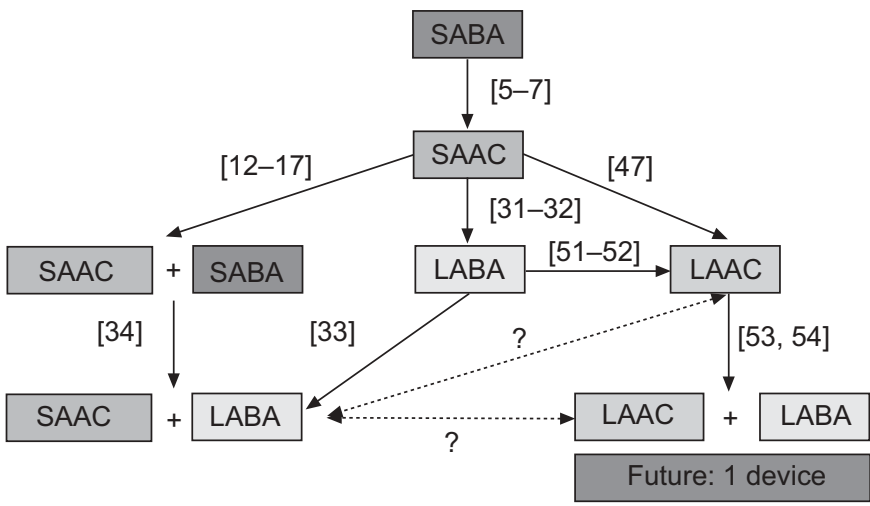

FIGURE 2. Inhaled bronchodilators in maintenance treatment of chronic obstructive pulmonary disease; historical evolution along the lines of evidence. Each block represents a class of inhaled bronchodilators or combination of bronchodilators as they became subsequently available on the market. The interconnecting full arrows point to the class with demonstrated superior effects on health outcomes (the evidence being provided by comparative studies referred to by the numbered references between brackets). Dashed interconnecting bidirectional arrows indicate the absence of comparative studies. SABA: short-acting $\beta_{2}$-adrenergic receptor agonist; SAAC: short-acting anticholinergic; LAAC: longacting anticholinergic; LABA: long-acting $\beta_{2}$-adrenergic receptor agonist.

$\mathrm{M}_{3}$-receptor selective anticholinergic agents. With respect to these outcomes, tiotropium performs well and sometimes superiorly in comparison with other inhaled short- and longacting bronchodilators, as summarised in figure 2 . The next step for the future probably resides in the combination of a LAAC with a LABA in a single device.

In this regard, tiotropium fulfils most of the objectives of chronic obstructive pulmonary disease management put forward by the global initiative for chronic obstructive lung disease guidelines [1] and enumerated in table 3 . The results of ongoing longer-term studies are awaited to see whether tiotropium maintenance treatment can meet the other important objectives not yet examined, i.e. prevention of disease progression and reduction of mortality. As subscribed by the recent review by TASHKIN et al. [60], maintenance bronchodilator treatment of chronic obstructive pulmonary disease patients, recommended for global initiative for chronic obstructive lung disease classes II and above [1], ideally

\begin{tabular}{lc} 
TABLE 3 & $\begin{array}{l}\text { Global initiative for chronic obstructive lung } \\
\text { disease objectives of COPD management: does } \\
\text { tiotropium meet them? }\end{array}$ \\
\hline Relieve symptoms & Yes \\
Improve exercise tolerance & Yes \\
Improve health status & Yes \\
Prevent and treat exacerbations & Yes \\
Prevent and treat complications & $?$ \\
Reduce mortality & ? UPLIFT study \\
Minimise side effects from treatment & Yes \\
Prevent disease progression & ? UPLIFT study \\
\hline
\end{tabular}

? UPLIFT: awaiting results from the UPLIFT study. COPD: chronic obstructive pulmonary disease. 
should start with the prescription of a long-acting antimuscarinic anticholinergic, in this particular case tiotropium, followed by a step-up to its combination with a long-acting $\beta_{2^{-}}$ adrenergic receptor agonist in case of suboptimal clinical effect. The next step in the future development of bronchodilators for the treatment of chronic obstructive pulmonary disease probably will reside in the combination of a longacting antimuscarinic anticholinergic with a long-acting $\beta_{2^{-}}$ adrenergic receptor agonist in one single inhalation device. Clinical benefit should be evaluated not only in terms of forced expiratory volume in one second, but perhaps more effectively in terms of hyperinflation (inspiratory capacity can be used as its spirometric surrogate), which appears more closely correlated to the above cited real-life outcomes.

\section{ACKNOWLEDGEMENTS}

The author wishes to thank L. Van Gijseghem for secretarial assistance, all Belgian and Dutch colleagues who participated in the Belgian-Dutch ipratropium controlled studies, and D. Moonen and P. Cornelissen from Boehringer Ingelheim who made these studies possible.

\section{REFERENCES}

1 Pauwels RA, Buist AS, Calverley PM, et al. Global strategy for the diagnosis, management and prevention of COPD. NHLBI/WHO global initiative for chronic obstructive lung disease (GOLD) workshop summary. Am J Respir Crit Care Med 2001; 163: 1256-1276, and 2003 update.

2 Barnes PJ. Neural control in human airways in health and disease. Am Rev Respir Dis 1986; 134: 1289-1314.

3 Barnes PJ. Muscarinic receptor subtypes in airways. Life Sci 1993; 52: 521-527.

4 Eglen RM, Hegde SS, Watson N. Muscarinic receptor subtypes and smooth muscle function. Pharmacol Rev 1996; 48: 531-565.

5 Gross NJ, Skorodin MS. Role of the parasympathetic system in airway obstruction due to emphysema. New Engl J Med 1984; 311: 421-425.

6 Ashutosh K, Lang H. Comparison between long-term treatment of chronic bronchitic airway obstruction with ipratropium bromide and metaproterenol. Ann Allergy 1984; 53: 401-406.

7 Braun SR, Mc Kenzie WN, Copeland C, et al. A comparison of the effect of ipratropium and albuterol in the treatment of chronic obstructive airway disease. Arch Intern Med 1989; 149: 544-547.

8 O'Donnell DE, Lam M, Webb KA. Spirometric correlates of improvement in exercise performance after anticholinergic therapy in chronic obstructive pulmonary disease. Am J Respir Crit Care Med 1999; 160: 542-549.

9 Teramoto S, Fukuchi Y. Improvements in exercise capacity and dyspnea by inhaled anticholinergic drug in elderly patients with chronic obstructive pulmonary disease. Age and Ageing 1995; 24: 278-282.

10 Oga T, Nishimura K, Tsukino $\mathrm{M}$, et al. The effects of oxitropium bromide on exercise performance in patients with stable chronic obstructive pulmonary disease. Am J Respir Crit Care Med 2000; 161: 1897-1901.

11 Pavia D, Bateman JR, Sheahan NF, et al. Effect of ipratropium bromide on mucociliary clearance and pulmonary function in reversible airways obstruction. Thorax 1979; 34: 501-507.

12 Jenkins CR, Chow CM, Fisher BL, et al. Ipratropium bromide and fenoterol by aerosolized solution. $\mathrm{Br} \mathrm{J} \mathrm{Clin}$ Pharmacol 1982; 14: 113-115.

13 Grassi V, Bruni B, Peccini F, et al. Acute on chronic comparative effects of a combination of fenoterol-ipratropium bromide and terbutaline in patients with chronic obstructive lung disease. Respiration 1986; 50: Suppl. 2, 226-231.

14 Barnabe R, Pirrelli M, Rossi M. Combined inhalation of fenoterol and ipratropium bromide in long-term therapy of chronic reversible airway obstruction. Respiration 1986; 50: Suppl. 2, 232-235.

15 Frith PA, Jenner B, Dangerfield R, et al. Oxitropium bromide. Dose-response and time-response study of a new anticholinergic bronchodilator drug. Chest 1986; 89: 249-253.

16 Combivent Inhalation Aerosol Study Group. Chronic obstructive pulmonary disease a combination of ipratropium and albuterol is more effective than either agent alone: an 85 day multicenter trial. Chest 1994; 105: 1411-1419.

17 Wilson JD, Serby CW, Menjoge SS, et al. The efficacy and safety of combination bronchodilator therapy. Eur Respir Rev 1996; 6: 39, 286-289.

18 Friedman M, Serby CW, Menjoge SS, et al. Pharmacoeconomic evaluation of a combination of ipratropium plus albuterol compared to ipratropium alone and albuterol alone in COPD. Chest 1999; 115: 635-641.

19 Benayoun S, Ernst P, Suissa S. The impact of combined inhaled bronchodilator therapy in the treatment of COPD. Chest 2001; 119: 85-92.

20 American Thoracic Society Statement. Standards for the diagnosis and care of patients with chronic obstructive pulmonary disease. Am J Respir Crit Care Med 1995; 152: S77-S120.

21 Siafakas NM, Vermeire $\mathrm{P}$, Pride NB, et al. Optimal assessment and management of chronic obstructive pulmonary disease (COPD). Eur Respir J 1995; 8: 1398-1420.

22 Tashkin DP. Multiple dose regimens: impact on compliance. Chest 1995; 107: 176S-182S.

23 Mellins RB, Evans D, Zimmerman B, et al. Patient compliance: are we wasting our time and don't know it? Am Rev Respir Dis 1992; 146: 1376-1377.

24 Ulrik CS. Efficacy of inhaled salmeterol in the management of smokers with chronic obstructive pulmonary disease: a single centre randomized, double-blind, placebo controlled, crossover study. Thorax 1995; 50: 750-756.

25 Grove A, Lipworth BJ, Reid P, et al. Effects of regular salmeterol on lung function and exercise capacity in patients with chronic obstructive airways disease. Thorax 1996; 51: 689-693.

26 Boyd G, Morice AH, Pounsford JC, et al. An evaluation of salmeterol in the treatment of chronic obstructive pulmonary disease (COPD). Eur Respir J 1997; 10: 815-821.

27 Jones PW, Bosh TK. Quality of life changes in COPD patients treated with salmeterol. Am J Respir Crit Care Med 1997; 155: 1283-1289.

28 Cazzola M, Matera MG, Santangelo G, et al. Salmeterol and formoterol in partially reversible severe chronic obstructive pulmonary disease: a dose-response study. Respir Med 1995; 89: 357-362. 
29 Benhamou D, Cuvelier A, Muir JF, et al. Rapid onset of bronchodilation in COPD: a placebo-controlled study comparing formoterol (Foradil ${ }^{\circledR}$ Aerolizer ${ }^{\mathrm{TM}}$ ) with salbutamol (Ventodisk ${ }^{\mathrm{TM}}$ ). Respir Med 2001; 95: 817-821.

30 Kottakis J, Della Cioppa G, Creemers J, et al. Faster onset of bronchodilation with formoterol than with salmeterol in patients with stable, moderate to severe COPD: results of a randomized, double-blind clinical study. Can Respir J 2002; 9: 107-115.

31 Mahler DA, Donohue JF, Barbee RA, et al. Efficacy of salmeterol xinafoate in the treatment of COPD. Chest 1999; 115: 957-965.

32 Dahl R, Greefhorst LAPM, Nowak D, et al. Inhaled formoterol dry powder versus ipratropium bromide in chronic obstructive pulmonary disease. Am J Respir Crit Care Med 2001; 164: 778-784.

33 Van Noord JA, de Munck DR, Bantje TA, et al. Long-term treatment of COPD with salmeterol and the additive effect of ipratropium. Eur Respir J 2000; 15: 878-885.

34 D'Urzo AD, De Salvo MC, Ramirez-Rivera A, et al. In patients with COPD treatment with a combination of formoterol and ipratropium is more effective than a combination of salbutamol and ipratropium. A 3-week, randomized, double-blind, within-patient, multicenter study. Chest 2001; 119: 1347-1356.

35 Liesker JJW, Van De Velde V, Meysman M, et al. Effects of formoterol (Oxis ${ }^{\circledR}$ Turbohaler ${ }^{\circledR}$ ) and ipratropium on exercise capacity in patients with COPD. Respir Med 2002; 96: 559-566.

36 Disse B, Speck GA, Rominger KL, et al. Tiotropium (Spiriva $\left.{ }^{\circledR}\right)$ : mechanistical considerations and clinical profile in obstructive lung disease. Life Sci 1999; 64: 457-464.

37 Takahashi T, Belvisi MG, Patel H, et al. Effect of BA679 BR, a novel long-acting anticholinergic agent, on cholinergic neurotransmission in guinea pig and human airways. Am J Respir Crit Care Med 1994; 150: 1640-1645.

38 Disse B, Reichl R, Speck G, et al. BA679 BR, a novel longacting anticholinergic bronchodilator: predicted and clinical aspects. Life Sci 1993; 52: 537-544.

39 Maesen FPV, Smeets JJ, Costongs MAL, et al. BA679 BR, a new long-acting anti-muscarinic bronchodilator: a pilot dose escalation study. Eur Respir J 1993; 6: 1031-1036.

40 Maesen FPV, Smeets JJ, Sledsens TJH, et al. Tiotropium bromide, a new long-acting anti-muscarinic bronchodilator: a pharmacodynamic study in patients with chronic obstructive pulmonary disease (COPD). Eur Respir J 1995; 8: 1506-1513.

41 Littner MR, Ilowite JS, Tashkin DP, et al. Long-acting bronchodilation with once-daily dosing of tiotropium (Spiriva) in stable chronic obstructive pulmonary disease. Am J Respir Crit Care Med 2000; 161: 1136-1142.

42 Van Noord JA, Smeets JJ, Custers FLJ, et al. Pharmacodynamic steady state of tiotropium in patients with chronic obstructive pulmonary disease. Eur Respir J 2002; 19: 639-644.

43 Chodosh S, Flanders JS, Kesten S, et al. Effective delivery of particles with the Handihaler ${ }^{\circledR}$ dry powder inhalation system over a range of chronic obstructive pulmonary disease severity. Journal of Aerosol Medicine 2001; 14: 309-315.

44 Casaburi R, Briggs DD, Donohue JF, et al. The spirometric efficacy of once-daily dosing with tiotropium in stable
COPD. A 13-week multicenter trial. Chest 2000; 118: 1294-1302.

45 Van Noord JA, Bantje TA, Eland ME, et al. A randomized controlled comparison of tiotropium and ipratropium in the treatment of chronic obstructive pulmonary disease. Thorax 2000; 55: 289-294.

46 Casaburi R, Mahler DA, Jones PW, et al. A long-term evaluation of once-daily tiotropium in COPD. Eur Respir J 2002; 19: 217-224.

47 Vincken W, van Noord JA, Greefhorst APM, et al. Improved health outcomes in patients with COPD during 1 year's treatment with tiotropium. Eur Respir J 2002; 19: 209-216.

48 Mahler DA, Weinber DH, Wells CK, et al. The measurement of dyspnea: contents, interobserver agreement and physiological correlates of 2 new clinical indexes. Chest 1984; 85: 751-758.

49 Jones PW, Quirk FH, Baveystock CM, et al. A self-complete measure of health status for chronic airflow limitation. Am Rev Respir Dis 1992; 145: 1321-1327.

50 Brusasco V, Hodder R, Miravitlles M, et al. Health outcomes following treatment for 6 months with once daily tiotropium compared with twice daily salmeterol in patients with COPD. Thorax 2003; 58: 399-404.

51 Oostenbrink JB, Rutten-van Mölken MPMH, van Noord JA, Vincken W. One-year cost-effectiveness of tiotropium vs. ipratropium to treat COPD. Eur Respir J 2004; 23: 241-249.

52 Donohue JF, van Noord JA, Bateman ED, et al. A 6-month, placebo-controlled study comparing lung function and health status changes in COPD patients treated with tiotropium or salmeterol. Chest 2002; 122: 47-55.

53 Van Noord JA, Aumann J, Janssens E, et al. Comparison of once-daily tiotropium, twice-daily formoterol and the free combination once-daily in patients with COPD. ATS 2003, Seattle. Am J Respir Crit Care Med 2003; 167: A320.

54 Van Noord JA, Aumann J, Janssens E, et al. Tiotropium maintenance therapy in patients with COPD and the 24-h spirometric benefit of adding once or twice daily formoterol during 2-week treatment periods. ATS 2003, Seattle. Am J Respir Crit Care Med 2003; 167: A320.

55 Belman M, Botnick WC, Shin JW. Inhaled bronchodilators reduce dynamic hyperinflation during exercise in patients with COPD. Am J Respir Crit Care Med 1996; 153: 967-975.

56 O'Donnell DE, Flüge T, Gerken F, et al. Effects of tiotropium on lung hyperinflation, dyspnea and exercise tolerance in COPD. Eur Respir J 2004; 23: 832-840.

57 Celli B, Zuwallack R, Wang S, Kesten S. Improvement in resting inspiratory capacity and hyperinflation with tiotropium in COPD patients with increased static lung volumes. Chest 2003; 124: 1743-1748.

58 Kanner RE, Anthonisen NR, Connett JE. Lower respiratory illnesses promote FEV1 decline in current smokers but not ex-smokers with mild chronic obstructive pulmonary disease. Am J Respir Crit Care Med 2001; 164: 358-364.

59 Donaldson GC, Seemungal TA, Bhowmik A, et al. Relationship between exacerbation frequency and lung function decline in chronic obstructive pulmonary disease. Thorax 2002; 57: 847-852.

60 Tashkin DP, Cooper CB. The role of long-acting bronchodilators in the management of stable COPD. Chest 2004; 125: 249-259. 